\title{
SOME FEEDING HABITS OF MOOSE IN YELLOWSTONE PARK
}

\author{
John F. McMiLLan 1 \\ Department of Zoology, University of Michigan, Ann Arbor, Michigan
}

\section{INTRODUCTION}

Moose, most majestic of all deer, command attention at all times and in all places. It is not unusual in Yellowstone Park to see over one hundred people per hour stop along the highway during the height of the tourist season to observe this animal. Moose are considered one of the prime attractions there.

Because of over-crowding of many species in a limited area and because of the obligation the Park Service has to the public, problems of wildlife management are particularly acute there. A complete monographic study of the moose with all of the intricate interrelationships is needed, but such a study would require years to complete.

Considerable interest has been shown in the moose of the region since Shiras (1913) made the initial study of the Yellowstone moose (Alces americana shirasi Nelson). Murie (1934) studied the moose of Isle Royale from a more strictly ecological approach and stressed the feeding habits. This paper is a portion of a study made on the feeding behavior of the moose of Yellowstone Park. Field studies include June 20 to September 7, 1947; June 4 to September 10, 1948; May 30 to September 10, 1949.

Yellowstone Park is located principally in the northwest corner of Wyoming. Except for some irregularities of boundary lines at the extreme northwest and northeast corners, the park extends into Montana 3.1 miles on the north and 2.05 miles into Montana and Idaho on the west. Willow Park and the adjacent Swan Lake Flat comprise the principal areas covered in this paper. These areas lie in a general north-south direction

\footnotetext{
1 Present address, International House, Chicago, Illinois.
}

paralleling the main park highway about midway between Mammoth Hot Springs and Norris Geyser Basin.

\section{Methods of Study}

Direct observations were used almost exclusively to determine the food and feeding habits of the moose. Binoculars $(7 \times 35 \mathrm{~mm}$. $)$ were used in the field observations. Representatives of species of plants that were eaten by the moose were collected and mounted according to accepted herbarium methods and submitted for identification to specialists in the various groups.

In all cases where the time element enters, such as rate of movement while feeding, time spent in feeding, etc., the time was determined by watch. Distances covered in feeding are estimates only. Accuracy of estimates was checked twice by measuring with a steel tape and was found to be as great as the study required.

\section{Plants Eaten}

Although moose are primarily browsing animals, in no sense are they restricted to browsing. In this study twenty-three species of plants were found to be eaten. From a total of 1,497 observations it was found that two species of willow constitute approximately 75 per cent of the diet, while aquatic plants total a little over 17 per cent, both based on frequency of utilization; on the same basis grasses, grasslike plants, and forbs make up only 7.9 per cent of the total. On the basis of time spent in feeding on each type, willows constituted 88.5 per cent of the diet, aquatic plants 9.3, grasses, grass-like plants and forbs 2.2 per cent.

Schultz (1942) lists a total of seventyone species of plants that were eaten by moose on the area involved in that study, 
and the list is admittedly incomplete. The area covered by the Montana study was several hundred times larger than the area used in the present one and involved three minor, but distinct, watersheds. Murie (1934) found a much greater utilization of trees and shrubs on Isle Royale than was found by either the present study or the Montana Survey. The reason for this is apparently the presence of a greater variety of species in a mixed hardwood and coniferous habitat than in the almost completely coniferous Yellowstone and Montana areas. Thus it appears that moose, while restricted in food preference to a certain degree, do have a wide range of selectivity. The greater the variety of species making up the plant cover of a par- ticular locality, the greater is the number of species eaten by the moose.

Feeding on Salix Geyeriana is approximately three times more frequent than on S. Wolfii. Of 1,115 observations of moose feeding on willows, $S$. Geyeriana accounts for 73.1 per cent in contrast to 26.9 percent for S. Wolfii. Table I shows the percentage of observations for both willows figured on the basis of all species of plants eaten; out of a total of 1,497 feeding observations, 54.5 per cent were made of moose feeding on $S$. Geyeriana and 20.0 per cent on $S$. Wolfii.

The reasons for the difference in degree of browsing on the two species are not clear, but certain hypotheses may be advanced. Van Dersal (1938) lists these

TABLE I. Distribution, abundance, number of observations, and percentages of the total of observations of utilization of plants eaten by moose

\begin{tabular}{|c|c|c|c|c|}
\hline Species & Occurrence & $\begin{array}{l}\text { No. observations } \\
\text { of utilization } \\
\text { by moose }\end{array}$ & $\begin{array}{l}\text { Per cent of total } \\
\text { observations }\end{array}$ & $\begin{array}{l}\text { Per cent total } \\
\text { feeding time }\end{array}$ \\
\hline $\begin{array}{l}\text { Shrubs } \\
\quad \text { Salix Geyeriana } \\
\text { S. Wolfi }\end{array}$ & $\begin{array}{l}A-W \\
A-W\end{array}$ & $\begin{array}{l}815 \\
300\end{array}$ & $\begin{array}{l}54.5 \\
20.0\end{array}$ & 88.5 \\
\hline $\begin{array}{l}\text { Aquatic plants } \\
\text { Heteranthera dubia } \\
\text { Myriophyllum sp. } \\
\text { Potamogeton alpinus } \\
\text { P. pectinatus } \\
\text { Utricularia vulgaris } \\
\text { Chara sp. }\end{array}$ & $\begin{array}{c}P-S c \\
M-S c \\
R-T S c \\
M-S c \\
M-S c \\
R-T S c\end{array}$ & $\begin{array}{r}78 \\
68 \\
4 \\
52 \\
57 \\
2\end{array}$ & 17.5 & 9.3 \\
\hline $\begin{array}{l}\text { Grasses } \\
\text { Agrostis hiemalis } \\
\text { Agropyron sp. } \\
\text { Deschampsia caespitosa } \\
\text { Glyceria pauciflora } \\
\text { Bromus ciliatus } \\
\text { Elymus glaucus } \\
\text { Melica bulbosa } \\
\text { Phleum alpinum } \\
\text { Poa sp. }\end{array}$ & $\begin{array}{l}S-S c \\
S-T S c \\
R-T S c \\
R-S m C \\
S-T S c \\
S-T S c \\
R-T S c \\
M-S c \\
M-S c\end{array}$ & $\begin{array}{r}6 \\
18 \\
3 \\
5 \\
3 \\
3 \\
3 \\
4 \\
37\end{array}$ & 5.4 & 1.6 \\
\hline $\begin{array}{l}\text { Forbs } \\
\text { Fragaria americana } \\
\text { Heracleum lanatum } \\
\text { Potentilla sp. }\end{array}$ & $\begin{array}{r}\mathrm{R}-\mathrm{TSc} \\
\mathrm{M}-\mathrm{TSc} \\
\mathrm{S}-\mathrm{TSc}\end{array}$ & $\begin{array}{r}1 \\
11 \\
2\end{array}$ & 0.9 & 0.5 \\
\hline $\begin{array}{l}\text { Miscellaneous } \\
\text { Carex sp. } \\
\text { Equisetum hiemale } \\
\text { Lusula Wahlenbergii }\end{array}$ & $\begin{array}{l}A-W \\
R-T S c \\
R-S m C\end{array}$ & $\begin{array}{r}23 \\
1 \\
1\end{array}$ & 1.6 & 0.1 \\
\hline
\end{tabular}

Scale used in above table: A-abundant; P-plentiful; $M$-moderate; S-scarce; $R$-rare; Wwide-spread; Sc-Scattered; TSc-thinly scattered; SmC-single small clump. 
willows as being equally palatable for domestic stock and there is no apparent reason why they should not be equally so for wild animals. De Nio (1938), in discussing food and feeding habits of both deer and elk, makes no distinction between different species of willows with reference to palatability. Young (1938) says that all forms of willows are equally palatable. The term "palatability" is defined by the U. S. Forest Service as that percentage of the readily accessibly herbage of a species that is eaten when the range is properly utilized.

The fact that $S$. Geyeriana is tall enough in many places to hide the moose while feeding may account for part of the difference in frequency of utilization. $S$. Wolfii is rarely more than three feet tall and can scarcely hide an adult moose even when lying down. Moose may tend to avoid browsing on $S$. Wolfii because it is so low that it may be less easily browsed than taller shrubs. On this study area it was noted that elk browsed more on $S$. Wolfii than on $S$. Geyeriana, but this was largely due, I think to the fact that most of the $S$. Wolfii was found on the west side of the area and, therefore, farther from the highway. The elk are much more wary than the moose in this locality and only rarely were found feeding within three hundred yards of the road. The fact that elk tend to be more of a grazing animal than moose may explain, in part, why they feed more frequently on $S$. $W$ olfii than do moose.

Grasses constitute a minor part of the moose's diet. Only 5.4 per cent of the feeding records refer to grasses. Poa sp., being the most abundant and widespread of the grasses on the area, was observed to be eaten thirty-seven times. Wheat grass, Agropyron sp., was utilized eighteen times. Although this grass is scarce and thinly scattered it was eaten much more frequently than other grasses that are more abundant. While the data are too few to say that there is a preference for Agropyron sp., it appears that there may be. The other seven species of grasses constitute less than 2 per cent of the total number of feeding records.

Grass-like plants, of which Carex sp. constitutes all but two of the records in this group, furnish only 1.6 per cent of the feeding records.

Only three species of forbs were observed to be utilized. They make up less than 1 per cent of the total. Almost certainly others were taken by the moose, but were not observed. No seasonal variation in the diet was noted during the period of study.

\section{Underwater FeEding}

In this area aquatic plants constitute a minor part of the moose's diet. Very little of the total feeding time is spent in the old beaver canals and streams of the area. Two factors operate to relegate aquatic feeding to a secondary position. The amount of aquatic vegetation that is available to the moose as compared to the amount of willow browse is very small, and the soft bottoms of the sluggish streams and beaver canals make feeding there difficult. It appears as if aquatic plants serve only as a condiment to the staple food.

Eight different species of aquatic plants known to be eaten by moose are found on the study area. The yellow water lily, Nymphaea polysepala, which is normally considered a staple part of the diet elsewhere, was not seen to be eaten at any time. Chara sp., a plant heavily encrusted with calcium salts and therefore not considered to be very palatable, was seen to be eaten on only two occasions. Spirogyra sp., was not seen to be eaten by the moose on this area during the period of study. All three of these species are rare and are found in small, isolated patches. The yellow water lily was found in only two places with very few plants in each patch. Late in the summer the water dried up where these plants grew, and the leaves died down to the underground stem. I believe they were not 
eaten simply because of the much greater availability of other species.

Heteranthera dubia was preferred above all others. In one instance a cow was seen to come from the woods and go directly to a patch growing in the shallow water of Obsidian Creek and feed on it for forty minutes. In getting to this place she ignored other aquatic plants which were easily available.

The water in the streams and canals was relatively shallow. In most places the depth ranged between six and twelve inches, except in a few places in Obsidian Creek where it was as much as six feet. Moose are capable of completely submerging themselves and feeding for as long as a minute without coming up to breathe. On this area, however, the water in which the moose fed was shallow enough so that it was largely a matter of simple grazing in the water. In eighty-six instances of moose feeding on submerged aquatic vegetation, the average length of time that the head was submerged was 10.3 seconds with a range of two to twenty-five seconds. The interval between submersions ranged from one to nineteen seconds, with an average of 4.6 seconds when feeding was continuous.

\section{Mineral Diet}

There are two small places in the study area where both moose and deer were seen to come to eat the soil. Numerous tracks indicated that elk also frequented them.

Often the moose would stand in Obsidian Creek and eat the soil of the bank. In one place about four feet long the bank is undermined about a foot. The bank here is wet due to seepage from a higher level. On one occasion a moose was seen to take a mouthful from underneath the overhang. Presumably the undermining was done by repeated eating of the soil by moose and elk.

On the opposite side of the stream and about thirty feet from the edge of the bank there is an area about thirty feet in diameter that is bare of vegetation, quite dry, and well trampled. It is rather high in the center, about two feet higher than the outer edge. I think possibly there may have been a beaver house on the spot in times past when beavers were more common in the area. This spot is also utilized as a source of minerals by moose, elk, and deer.

Samples of soil were taken from both places and qualitative analyses run on them. From the data contained in Table II it appears that the chlorides and sulfates of sodium and calcium were the minerals sought by the moose. It is questionable whether the iron was sought.

The moose were never seen at the licks during the day because they are within twenty-five yards of one of the main parking areas on the highway and there were cars parked there almost coritinuously during the day. Moose were observed at the licks as early as 7 P.M. and as late as $10: 30$ P.M.

The length of time the moose spent at the licks was always short, varying from several minutes to as long as half an hour. Both bulls and cows frequented the licks. No more than three were ever seen there at any one time, and that only once. Frequently there were two, but generally only one.

TABLE II. Qualitative analysis of soil samples obtained from mineral licks

\begin{tabular}{|c|c|c|c|c|c|c|c|c|}
\hline Sample & $\mathrm{Ca}$ & $\mathrm{Na}$ & $\mathrm{Cl}$ & $\mathrm{SO}_{4}$ & $\mathbf{M g}$ & $\mathbf{K}$ & PO, & $\mathrm{Fe}$ \\
\hline $\begin{array}{l}\text { Moist bank of } \\
\text { creek }\end{array}$ & Sl. & SI. & S1. & SI. & Neg. & Neg. & Neg. & Neg. \\
\hline $\begin{array}{l}\text { Dry soil } 30 \mathrm{ft} \text {. } \\
\text { back from bank }\end{array}$ & Mod. & Mod. & Mod. & Mod. & Neg. & Neg. & Neg. & Faint \\
\hline
\end{tabular}

Scale: Neg., negative; Faint; Sl., slight; Mod., moderate. 
TABLE III. Frequency and percentage of types of browsing on willows

\begin{tabular}{|c|c|c|c|}
\hline How browsed & S. Geyeriana & S. Wolfii & $\begin{array}{l}\text { Both } \\
\text { species }\end{array}$ \\
\hline $\begin{array}{l}\text { No. twigs nipped } \\
\text { Per cent nipped }\end{array}$ & $\begin{array}{l}435 \\
38.6\end{array}$ & $\begin{array}{l}518 \\
41.3\end{array}$ & $\begin{array}{l}953 \\
39.9\end{array}$ \\
\hline $\begin{array}{l}\text { No. twigs stripped } \\
\text { Per cent stripped }\end{array}$ & $\stackrel{80}{7.0}$ & $\begin{array}{l}99 \\
7.7\end{array}$ & $\begin{array}{l}179 \\
7.5\end{array}$ \\
\hline $\begin{array}{l}\text { No. twigs nipped } \\
\text { and stripped }\end{array}$ & & 639 & 1,251 \\
\hline $\begin{array}{l}\text { Per cent nipped and } \\
\text { stripped }\end{array}$ & 54.4 & 50.8 & 52.6 \\
\hline $\begin{array}{l}\text { Total no. twigs } \\
\text { examined }\end{array}$ & 1,127 & 1,256 & 2,383 \\
\hline
\end{tabular}

\section{ManNer of FEeding}

The moose is not a dainty browser like the deer; neither is it a coarse browser like the elk, when the elk is forced to browse. The browsing of moose can be divided into three categories, nipping, stripping, and a combination of these. In the process of nipping, the ends of the twigs are grasped between the lower incisors and premaxillaries of the upper jaw and broken off sharply by an upward or forward motion of the muzzle. The length of twig removed in this manner is relatively short, only two to four inches of the leafy end. The number of twigs taken in a single mouthful is variable, depending on the density of twigs on the central shoot. It is necessarily limited, perhaps being half a dozen twigs at the most. The lack of upper incisors precludes the possibility of cutting off large twigs by this means. The largest twig known to have been nipped by moose was three-sixteenths of an inch in diameter.

In stripping, the upper lip and tongue are used to gather a mouthful very much in the same manner as a horse. With an upward twist of the head the twigs are, in effect, pulled through the mouth, thus stripping them of leaves and small lateral shoots. The length of shoots stripped of leaves is also variable. The majority of twigs are stripped of their leaves for a length of four to twelve inches.

In feeding on willows very often the moose will strip off some leaves from the proximal portion of the twig and nip off the terminal bud as the twig is pulled through the mouth. The effect of removal of the lateral leaves and the terminal bud has a decidedly different effect on the response of the willow to browse injury as will be shown later.

Adult moose of this area have no diffculty in grazing on grass and sedge, but calves, because of their long front legs and relatively short neck, find it is necessary to kneel to graze.

In order to determine what part of the moose's feeding on willows consisted of nipping the ends of the shoot, stripping the leaves, and both, counts were made in six different places immediately after adult moose had fed there. Only twigs that were freshly browsed were counted so as to eliminate those browsed by elk. Table III shows that in browsing, over 50 per cent of a total of 2,383 twigs are both nipped and stripped in the process. When a shoot is stripped, quite obviously the terminal bud would stand a good chance of being removed. Approximately 40 per cent of the moose's feeding is done by nipping the ends of the twigs with no injury to the remaining lateral buds, leaves, and shoots. Only 7.5 per cent of the twigs were stripped leaving the terminal bud uninjured. There is no significant difference between the two species of willows in the results of browsing.

\section{Rate of Movement in Feeding}

The rate of movement while feeding is characteristic of different species of animals. The white-tail deer, for example, nip here and there with very little pause at any one place. Moose, however, are not of such a nervous temperament and when undisturbed may remain in one clump of willows for several days, leaving only to drink. One cow remained for about two weeks in the same clump where she had calved. An old beaver canal partially filled with water came up to the edge of the clump so there was no necessity for her to go farther to drink. 
By the time she left the copse on July 5 all of the twigs within reach had been so severely browsed that many of them were dying.

Another cow that calved very late in the season (June 28, 1948) likewise remained in an area of about two acres for ten days. When disturbed she would simply move from one clump to another.

Thirty-six feeding moose were kept under observation for a total of 1,045 minutes in order to determine their rate of movement while browsing on willows. The distance moved in a five minute interval was estimated. The results obtained from the sample show that in each five minute interval a moose will move an average of three yards, with a range of one to six yards, while feeding undisturbed on willows. Cow 8-7 was observed on August 22, 1948 to feed for twenty minutes without moving more than eight or ten feet; however, this cow had suffered an injury in some unknown manner to her left hind leg and moved about with considerable difficulty.

No appreciable difference in rate of movement was noted whether feeding in the open, or the edge of a clump, or in the center of a clump. The density of growth in the center of a clump of willows offers some resistance to movement, but with an animal as large and as powerful as a moose it apparently is not great enough to hinder them appreciably in moving about. The same rate of movement was observed whether feeding on the low, densely growing $S$. Wolfii or $S$. Geyeriana.

When disturbed by tourists, or if I came too close, or surprised them suddenly, the pattern of feeding behavior of the moose frequently changed. Almost invariably when surprised, the moose would pause long enough to survey the situation. They did not dash away madly without knowing what the danger was. Very frequently the cows would pinch their hind legs together and urinate on them before running. Bulls did not show this manifestation of alarm. Murie
(1934) suggests that this may be a reflex action induced by fright. No other explanation seems to be plausible.

If frightened early in the feeding period the moose would move away to a different spot and commence feeding again, whereas if disturbed late in the feeding period they would be more apt to cease feeding altogether and seek out their bedding areas. The more nervous animals would leave the feeding grounds without lingering; others would move off more or less leisurely, feeding as they went.

While feeding in the streams on aquatic vegetation movement is necessarily very slow. There are two types of streams on the study area. One is Obsidian Creek which is swift, cold, and shallow enough that it can be waded easily. However, here and there holes can be found as much as six feet deep. In places where the water is shallow, six inches to two feet, and where it is not too swift the following plants are found growing: Heteranthera dubia, Nymphaea polysepala, Myriophyllum sp., Potamogeton alpinus, $P$. pectinatus, Utricularia vulgaris, Glyceria pauciflora, and Chara sp.

All of these aquatic plants grow in soft mud of the stream bed, except Glyceria pauciflora, which grows on a coarse gravel bottom. In feeding on the muddy stream bed the moose sink into the mud so that the water reaches belly height.

The other type of stream is the slow, more or less stagnant, intermittent stream, some of which may be a part of the canal system constructed by beavers in former times. During late summer many dry up completely, especially the old canals. The bottoms are soft, moose sinking in the mud as much as three feet. The water, however, is quite shallow, averaging six to twelve inches deep. The same species of plants as listed above grow in this type of stream with the exception of Glyceria pauciflora. In addition to the plants just listed, the alga, Spirogyra sp., is found in the more stagnant pools late in the summer. No moose was seen to eat Spirogyra, but Mr. Rudolph Grimm, a 
ranger of the park, states that in the winter he frequently has seen them eat it from the streams that are kept open by the runoff from hot springs and geysers. Townsend and Smith (1933) cite observations to show that this alga is actively sought by white-tailed deer of the Adirondacks. They state that in one afternoon twentyfour white-tails were seen in an area of about thirty acres feeding on an alga that was thought to be Spirogyra. It is not unreasonable to presume that, in time of low food supply it may figure more prominently in the diet of the moose than was observed in my study.

Because of the impediment offered by depth of water and soft bottoms and also by the relatively concentrated supply of aquatic vegetation as compared with willow the rate of movement in aquatic feeding is very slow. One moose was observed to feed twenty minutes, and another for fifteen minutes, without moving more than three feet. In one instance where the vegetation was sparse another moose moved one yard in three minutes. The average rate of moving while feeding on aquatics was 0.1 yard per minute. This figure was obtained from seventy-three minutes of observation on six different moose.

\section{Height of Browsing}

To determine the height at which moose browse on willows in summer feeding, data were gathered in the following manner. After an animal had finished feeding in a clump the height of randomly selected twigs was measured and recorded in the following height intervals in feet; $0.75-$ $1.9 ; 2.0-3.9 ; 4.0-5.9 ; 6.0-7.9 ; 8.0-9.9$; 10.0-11.9. The twigs to be measured were randomly selected by setting up vertical lines every two feet and counting all freshly browsed twigs six inches on either side of that line from the ground to the top of the clump. There were as many places from which measurements were taken in the center as at the periphery of the clump. There proved to be no dif-
TABLE IV. Height of browsing on willows by eleven adult moose

\begin{tabular}{r|c|c|c|c}
\hline \hline & \multicolumn{2}{|c|}{$S$. Geyeriana } & \multicolumn{2}{|c}{$S$. Wolfi } \\
\cline { 2 - 5 } Ht. in feet & $\begin{array}{c}\text { Browsed } \\
\text { twigs } \\
\text { counted }\end{array}$ & Per cent & $\begin{array}{c}\text { Browsed } \\
\text { twigs } \\
\text { counted }\end{array}$ & Per cent \\
\hline $0.75-1.9$ & 117 & 16.5 & 191 & 33.0 \\
$2.0-3.9$ & 325 & 45.7 & 388 & 67.0 \\
$4.0-5.9$ & 246 & 34.6 & & \\
$6.0-7.9$ & 23 & 3.2 & & \\
$8.0-9.9$ & 0 & 0 & & \\
$10.0-11.9$ & 0 & 0 & & \\
\hline
\end{tabular}

ference of statistical significance between the amount of browsing done at the edge and in the center in the clumps from which the data were gathered. There may be a greater concentration on the peripheral layer in $S$. Wolfii if the clump is particularly dense and if the brooming effect has been such that short, stiff branches are produced that may be resistant to penetration by the prehensile lip and extremely flexible tongue of the moose. These data were gathered from eleven different moose and are summarized in Table IV.

A total of 711 twigs was measured for S. Geyeriana and 579 for S. Wolfii, a sufficient number in each case to yield statistically significant results. In $S$. Geyeriana 80 per cent of the browsing occurs within a four foot vertical range and two-thirds of all browsing of $S$. Wolfi occurs within a two foot range. The mean height of browsing on S. Geyeriana is $3.49 \mathrm{ft}$. and for $S$. Wolfi it is $2.34 \mathrm{ft}$. with standard deviations of 0.48 and 0.93 ft., respectively.

Even though $S$. Geyeriana reaches a height of twelve feet no browsing during the summer was ever seen to occur above seven, however, browsing is evident as high as twelve feet on some willows. It is believed that when browsing occurs above seven feet it is done in winter when snow forces the pliant shoots toward the ground, or if the snow is sufficiently crusted, the moose may be able to walk on top of it. In summer feeding the moose were not seen to "ride" down the 
shrubs or to break them off as Murie (1934) observed on Isle Royale.

Table IV shows that the greatest amount of browsing occurs in the $2-4 \mathrm{ft}$. height interval. With $S$. Wolfii the maximum height falls within this interval and the greatest amount of browsing on this species occurs in the upper third or peripheral layer of the clump. In S. Geyeriana there is a greater variability of height of browsing because of the greater height of the plant and as the height increases there is a greater relative amount of browsing in the lower part of the willow where it is more easily taken by the moose. Willows are not browsed at greater heights during summer because of the greater availability of foliage at more convenient levels. Concentration of previous browsing within a relatively narrow vertical range on the shrub has caused the brooming effect to be more pronounced there than at other levels. Up to a certain point the increase in lateral branches would tend to produce a greater foliage at that level. It is suggested that possibly moose would be more strongly attracted to browse at that level because of the increased amount of forage, thus setting up a vicious cycle that tends to concentrate browsing.

Characteristic feeding habits are to some extent dependent on the size and general morphology of the animal. In general the larger the animal the greater would be the range in height from which food could be obtained from a tree or shrub. Moose, being the largest member of the deer family, are able to obtain food from ground level to as high as ten or twelve feet if necessity demands. Possibly the pendant and highly flexible upper lip of the moose is one factor which causes the moose to be a browsing, rather than a grazing animal. Allee et al. (1949, p. 241) indicate a possible relationship between the flexible lip structure and browsing habit in the black rhinoceros and elephant of South Africa as contrasted with the grazing habit of the white rhinoceros which possesses square lips.

\section{Peripheral and Central Browsing}

In order to determine whether there was any preference exercised for browsing either the edge or the center of a clump, approximately 750 unbrowsed twigs were marked with weatherproof tags on September 1,1947 . The tags were equally distributed between shoots in the outer four feet of the clump and the center. The outer four feet were chosen arbitrarily as defining the periphery because moose and elk can easily browse in that far from the edge without penetrating the clump. The size of the copse chosen for tagging was approximately twenty-five by seventy-five feet and was made up entirely of $S$. Geyeriana ranging in height from three to six feet. The tags were widely scattered throughout the clump so as to preclude the possibility of all tagged shoots being browsed by any one animal at any one time.

The plot was examined on June 9, 1948 to see if any preference had been exercised in browsing. There is no positive way of determining how much of the browsing was done by moose and how much by elk. The question to be answered was simply whether the willow clumps suffer greater browsing at the edge, where feeding appears to be easier, or in the center where movement would seem to be more difficult. The effect on the willows for all practical purposes would be the same if done by elk or if done by moose.

The results of checking the plot showed that in the periphery 13.1 per cent of the tagged twigs had been browsed, while in the center 9.3 per cent had been browsed. The difference in the amount of browsing done in the edge of the clump over that done in the center proved not to be statistically significant.

It was planned to check the plot again at the end of the summer of 1948 but within a space of several days beavers cut most of the shrubs that bore the tags at 
the edge of clump, thus making further comparison impossible.

The results of the experiment, findings concerning rate of movement of moose while feeding willows, and observations on feeding elk tend to support each other. The fact that there is no apparent selectivity of location within a clump where browsing may occur indicates that density of willow growth offers no impediment to feeding. For the period concerned, the indications are that both the edge and center of a clump are browsed about equally; however, as pointed out elsewhere, factors such as elk feeding in a compact group, and depth of snow may, over a longer period, cause the shoots at the edge of a clump to be browsed more severely than more centrally located ones.

\section{Summary}

A study of the feeding habits of moose was conducted in a limited area of northwestern Yellowstone Park during the summers of 1947, 1948, and 1949. The following conclusions can be drawn:

1. Approximately 88 per cent of the food consists of willow browse; 9.3 per cent consists of aquatic plants; the remainder of the diet is made up of forbs and sedges.

2. Because of the character of the streams in this area, underwater feeding is of little importance.

3. Moose came regularly to mineral licks for the chlorides and sulfates of sodium and calcium contained in the soil. Iron was present in the soil, but it is doubtful if this attracted the moose.

4. In feeding on willows, the moose removes the tender browse by either nipping off the end of the twig, by stripping the small lateral twigs and leaves, or by stripping the lateral twigs and nipping the terminal as well.

5. While feeding undisturbed a moose moves slowly taking a few mouthfuls from one place and some from another. The average rate of movement is three yards every five minutes. When feeding on aquatic vegetation the moose moves more slowly; depth of water, character of stream bottom, and abundance of the food sought, determine the rate of movement.

6. The height through which moose will feed varies from grazing at ground level to browsing as high as seven feet. About 56 per cent of all browsing is done at a level between two and four feet. Willows may be browsed higher in winter.

7. There is no significant difference in the amount of browsing done at the edge of a copse and in the center.

\section{REFERENCES}

Allee, W. C., Alfred E. Emerson, Orlando Park, Thomas Park, and Karl P. Schmidt. 1949. Principles of animal ecology. Philadelphia: W. B. Saunders.

De Nio, R. M. 1938. Elk and deer food and feeding habits. Trans. Third North Amer. Wildl. Conf., Washington, D. C.

Murie, Adolph. 1934. The moose of Isle Royale. Univ. Mich. Mus. Zool. Misc. Publ., 25. Univ. Mich. Press, Ann Arbor, Mich.

Schultz, Wm. Montana moose survey. (Unpublished.) Montana Fish and Game Comm., Helena, Mont.

Shiras, George, 3rd. 1913. Wild animals that took their own pictures by day and night. Nat. Geog. Mag., 23 : 763-834.

Townsend, M. T., and M. W. Smith. 1933. The white-tailed deer of the Adirondacks. Roosevelt Wildl. Bull., 6 : 201-202.

Van Dersal, W. R. 1938. Native woody plants of the United States. U. S. D. A. Misc. Publ., 303.

Young, Vernon A. 1938. The carrying capacity of big game range. Jour. Wildl. Mgt., 2: 131-134. 